\title{
QUÍMICA E SUSTENTABILIDADE: NOVAS FRONTEIRAS EM BIOCOMBUSTÍVEIS
}

\author{
Claudio J. A. Mota*,\# e Robson S. Monteiro** \\ Universidade Federal do Rio de Janeiro, Instituto de Química, Av Athos da Silveira Ramos 149, CT B1 A., 21941-909 Rio de Janeiro - RJ, Brasil
}

Recebido em 4/7/13; aceito em 30/8/13; publicado na web em 18/9/13

\begin{abstract}
CHEMISTRY AND SUSTAINABILITY: NEW FRONTIERS IN BIOFUELS. This contribution discusses the state of the art and the challenges in producing biofuels, as well as the need to develop chemical conversion processes of $\mathrm{CO}_{2}$ in Brazil. Biofuels are sustainable alternatives to fossil fuels for providing energy, whilst minimizing the effects of $\mathrm{CO}_{2}$ emissions into the atmosphere. Ethanol from fermentation of simple sugars and biodiesel produced from oils and fats are the first-generation of biofuels available in the country. However, they are preferentially produced from edible feedstocks (sugar cane and vegetable oils), which limits the expansion of national production. In addition, environmental issues, as well as political and societal pressures, have promoted the development of $2^{\text {nd }}$ and $3^{\text {rd }}$ generation biofuels. These biofuels are based on lignocellulosic biomass from agricultural waste and wood processing, and on algae, respectively. Cellulosic ethanol, from fermentation of cellulose-derived sugars, and hydrocarbons in the range of liquid fuels (gasoline, jet, and diesel fuels) produced through thermochemical conversion processes are considered biofuels of the new generation. Nevertheless, the available $2^{\text {nd }}$ and $3^{\text {rd }}$ generation biofuels, and those under development, have to be subsidized for inclusion in the consumer market. Therefore, one of the greatest challenges in the biofuels area is their competitive large-scale production in relation to fossil fuels. Owing to this, fossil fuels, based on petroleum, coal and natural gas, will be around for many years to come. Thus, it is necessary to utilize the inevitable $\mathrm{CO}_{2}$ released by the combustion processes in a rational and economical way. Chemical transformation processes of $\mathrm{CO}_{2}$ into methanol, hydrocarbons and organic carbonates are attractive and relatively easy to implement in the short-to-medium terms. However, the low reactivity of $\mathrm{CO}_{2}$ and the thermodynamic limitations in terms of conversion and yield of products remain challenges to be overcome in the development of sustainable $\mathrm{CO}_{2}$ conversion processes.
\end{abstract}

Keywords: biofuels; biomass; $\mathrm{CO}_{2}$.

\section{INTRODUÇÃO}

A Sociedade Brasileira de Química (SBQ), sempre atenta ao seu papel de discutir e propor soluções para temas de interesse nacional relacionados à área de Química, vem desenvolvendo inúmeras iniciativas, que também visam induzir políticas de C\&T de interesse geral. O Censo da Química no País ${ }^{1}$ é uma das mais recentes iniciativas, que visa debater com a comunidade assuntos estratégicos de interesse do país por meio de position papers, que descrevem a situação e desafios a serem vencidos em diversos temas centrais. A questão da energia é um dos temas centrais citados e no qual o presente artigo pretende contribuir para o debate, colocando a questão dos biocombustíveis e a utilização racional do $\mathrm{CO}_{2}$ em contraponto aos combustíveis de origem fóssil, que além de finitos, causam sérios problemas ambientais.

$\mathrm{O}$ século XX associou a Química à poluição ambiental, à degradação da flora e fauna, e às mudanças climáticas que o mundo vivencia. Grande parte deste sentimento está relacionado à indústria do petróleo, que deslanchou mundialmente no século passado trazendo conforto e bem estar para as pessoas, mas também deixando um rastro de poluição e desastres nunca antes visto na história do planeta. A sociedade moderna não quer abrir mão das comodidades e benefícios que a indústria do petróleo provê, como o uso de combustíveis de alto poder energético para movimentar veículos, assim como plásticos e produtos químicos diversos que hoje fazem parte do cotidiano das pessoas. Por outro lado, a sociedade também não aceita mais o custo ambiental negativo que a indústria do petróleo cobrou no século passado, com acidentes que causaram grandes devastações

*e-mail: cmota@iq.ufrj.br

"INCT Energia e Ambiente, UFRJ, Rio de Janeiro, Brasil

**Catalysis Consultoria Ltda., Avenida das Américas 7837, B1 2/401, 22793 -

081 Rio de Janeiro - RJ, Brasil à flora e fauna, bem como o aumento da temperatura do planeta, pela emissão excessiva de $\mathrm{CO}_{2}$, que retém grande parte do calor que deveria ser emitido para o espaço. Conjugar estas duas necessidades é um desafio que se coloca para a Química no século XXI.

Ciente do preço ambiental que os processos químicos industriais cobram na sua implantação, Paul Anastas formulou² na década de 1990 os princípios da chamada Química Verde. O conceito utilizado foi o de causar menor impacto ao ambiente e às pessoas. Dentre os 12 princípios formulados por Anastas para a Química Verde estão o uso de matérias-primas renováveis, a diminuição ou mesmo eliminação de resíduos e subprodutos e o uso de processos catalíticos. Atualmente, a Química Verde vem avançando a passos largos, sobretudo no que tange o uso de matérias-primas renováveis. O Brasil é pioneiro neste aspecto, com programas regulares sobre o uso de biocombustíveis desde a década de 1970. Porém, o conceito de Química Verde precisa ser ampliado de forma a abranger a questão da sustentabilidade. Hoje, a emissão de gases do efeito estufa é um dos principais problemas ambientais do mundo, podendo levar a um aumento significativo da temperatura do planeta em um futuro próximo, com graves consequências para o meio ambiente e para a economia das nações. Assim, a inclusão de um $13^{\circ}$ princípio, que atenda a esta questão da sustentabilidade, se faz necessária, ampliando o contexto de uma Química Verde para uma Química Sustentável.

A matriz energética mundial ainda é muito centrada em fontes fósseis, como petróleo, carvão e gás natural (Figura 1). Estas fontes respondem por cerca de $80 \%$ do consumo mundial de energia.

O Brasil tem uma matriz muito mais sustentável, na qual cerca de $45 \%$ vem de fontes renováveis, como hidrelétrica e biomassa (Figura 2). Entretanto, nosso país consome anualmente cerca de $2 \%$ do total da energia consumida no mundo, servindo mais como modelo a ser seguido do que efetivamente contribuindo para a sustentabilidade do planeta. É neste ponto que devemos continuar dando o bom exemplo, 


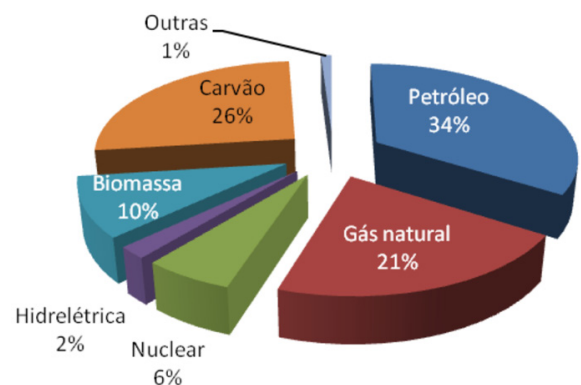

Figura 1. Matriz energética mundial em 2007, correspondendo a 239 milhões de toneladas equivalentes de petróleo

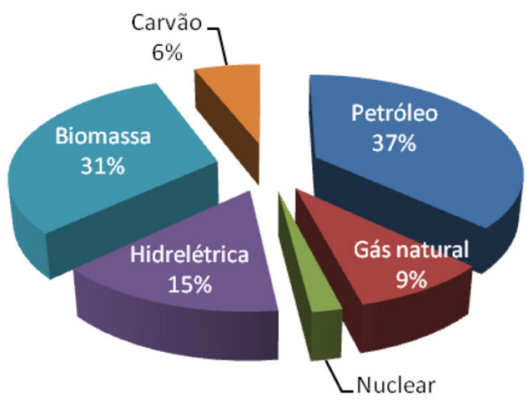

$2 \%$

Figura 2. Matriz energética brasileira em 2007, correspondendo a 12 bilhões de toneladas equivalentes de petróleo

e debatendo com as demais nações do planeta a necessidade de mudança na matriz energética global.

O país foi pioneiro no uso de biocombustíveis e tem um potencial enorme neste campo. O Brasil inova no uso de matéria-prima renovável na indústria química e deve avançar, também, na questão do uso do $\mathrm{CO}_{2}$. Este gás é emitido em grande escala na queima de combustíveis fósseis e está associado ao aumento da temperatura global. O pré-sal trouxe um novo alento às pretensões do país de se tornar uma potencia energética, podendo ser alçado a um dos maiores produtores mundiais, em poucos anos. Contudo, as reservas de gás natural e gás associado do pré-sal possuem altos teores de $\mathrm{CO}_{2}$ que, se colocadas na atmosfera, poderão dar ao país o incômodo título de campeão mundial da emissão deste gás. Nas próximas sessões a questão dos biocombustíveis e da utilização racional e econômica do $\mathrm{CO}_{2}$ serão tratadas, de forma a se buscar uma Química Sustentável, na qual as necessidades das gerações atuais sejam supridas sem que as necessidades das gerações futuras estejam ameaçadas pela devastação total de recursos naturais e mudanças climáticas.

\section{BIOCOMBUSTÍVEIS}

De forma geral, podemos definir biocombustíveis como todo combustível oriundo de matéria-prima renovável, sobretudo de origem vegetal. $\mathrm{O}$ ciclo do carbono passa pela absorção do $\mathrm{CO}_{2}$ da atmosfera pelas plantas e outros organismos vivos que realizam a fotossíntese, sendo transformado em carboidratos, triglicerídeos e outras substâncias orgânicas. Assim, os biocombustíveis têm um balanço neutro em termos de carbono, pois o $\mathrm{CO}_{2}$ emitido na queima pode ser reabsorvido pelas plantas no processo de fotossíntese.

Há muita discussão sobre os benefícios reais dos biocombustíveis, pois argumenta-se que no seu processo de produção, incluindo também a fase de plantio e colheita, gasta-se grandes quantidades de energia fóssil na produção de fertilizantes e outros insumos. Todavia, cada caso é particular e depende do tipo de matéria-prima empregada. A cana de açúcar é a mais indicada para o etanol de $1^{\text {a }}$ geração, produzindo de oito a dez vezes mais energia do que a usada no processo de produção. Por outro lado, o milho tem um balanço pouco atrativo, pois fornece basicamente a mesma quantidade de energia utilizada no processo de produção. A melhoria dos processos de cultivo e o uso de novos cultivares são tópicos a serem melhorados na questão dos biocombustíveis.

\section{Biocombustíveis de $\mathbf{1}^{\text {a }}$ geração}

Os biocombustíveis de $1^{\text {a }}$ geração são aqueles cujo processo produtivo encontra-se bem desenvolvido e são produzidos a partir de matérias-primas de origem alimentícia. Encaixam-se nesta categoria o etanol de fermentação de açúcares e o biodiesel obtido a partir de óleos e gorduras. Ambos biocombustíveis são produzidos em grande escala no país por meio de processos bem conhecidos.

O etanol é produto da fermentação de açúcares simples, como a glicose, usando leveduras do gênero Saccaromyces. O caldo da cana contém cerca de 15 a $20 \%$ de sacarose, que por hidrólise é convertida em glicose e frutose, as quais são então fermentadas a etanol e $\mathrm{CO}_{2}$ (Esquema 1).

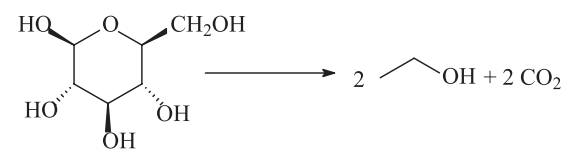

Esquema 1. Fermentação de glicose para produzir etanol

Materiais amiláceos como o milho também podem ser usado como fonte de glicose. O processo é realizado em regime de batelada numa temperatura entre 26 e $35^{\circ} \mathrm{C}$ e pH na faixa de 4 a 5 . O etanol é separado por destilação e o resíduo, também chamado de vinhaça ou vinhoto, pode ser usado como fertilizante no plantio e crescimento da cana.

A produção de etanol de $1^{\text {a }}$ geração no Brasil foi da ordem de 21 bilhões de litros em $2011 .^{3} \mathrm{O}$ país perdeu o posto de maior produtor mundial deste biocombustível para os Estados Unidos, que produziram neste mesmo ano cerca de 50 bilhões de litros deste biocombustível. ${ }^{4}$ A competição com a produção de alimentos e a mecanização do processo de colheita da cana vêm suscitando discussões sobre o papel social do bioetanol. A balança pode pesar a favor com a introdução dos processos de $2^{\text {a }}$ geração, que aproveitarão a celulose como matéria-prima, diminuindo a pressão sobre os alimentos.

Outro biocombustível de $1^{\text {a }}$ geração importante é o biodiesel. ${ }^{5}$ Ele é, normalmente, obtido a partir de óleos e gorduras pelo processo de transesterificação com alcoóis de cadeia pequena na presença de catalisadores ácidos ou, preferencialmente, básicos (Esquema 2). O metanol é o principal álcool usado na produção do biodiesel, apesar de ser oriundo de fonte fóssil. O etanol, mesmo vindo de fonte renovável, é mais caro e ocasiona alguns problemas técnicos no processo produtivo, que é normalmente mais lento e complexo em comparação ao processo com metanol.<smiles>[R]C(=O)OCC(COC([R])=O)OC([R])=O</smiles><smiles></smiles>

Esquema 2. Transesterificação de triglicerídeos para produção de biodiesel

Diferentemente do etanol, que no Brasil é produzido exclusivamente da cana-de-açúcar, o biodiesel tem diversas fontes de matérias-primas. Atualmente, o óleo de soja responde por cerca de 
$80 \%$ do biodiesel produzido no país. O sebo animal participa com $15 \%$, ficando o restante para outras matérias-primas, como a palma e o algodão. Esta diversidade de matérias-primas leva a processos produtivos diferenciados, assim como a biocombustíveis com diferentes propriedades. Por exemplo, o sebo animal possui alta acidez, na forma de ácidos graxos livres, e requer tratamento prévio, pois não pode ser usado diretamente na transesterificação com catalisadores básicos. Já o biodiesel de soja possui grande número de insaturações na cadeia, pois o óleo de soja é rico nos ácidos linoléico e linolênico, com duas e três insaturações na cadeia, respectivamente. O maior grau de insaturação da molécula de biodiesel leva a uma menor resistência à oxidação, requerendo aditivos específicos, os quais são, em sua maioria, importados e oriundos de fontes fósseis.

O glicerol ou glicerina, obtido no processo em torno de $10 \%$ em peso, também necessita ser adequadamente utilizado. Atualmente, há um excedente cerca de 10 vezes maior que a demanda tradicional deste produto, que se concentra nos setores farmacêuticos, alimentícios e de higiene pessoal. $\mathrm{O}$ uso da glicerina de produção do biodiesel na fabricação de insumos químicos diversos tem merecido grande atenção nos últimos anos. ${ }^{6}$ A grande funcionalidade da molécula, com três grupos hidroxila, aliada à farta oferta e baixo custo, torna a glicerina uma plataforma interessante para a obtenção de diversos produtos químicos (Figura 3).

Tanto o etanol como o biodiesel são utilizados como biocombustíveis no Brasil. O etanol é usado diretamente como combustível em motores do ciclo Otto e também misturado à gasolina, em percentual que varia de 20 a $25 \%$ em volume. O biodiesel é, atualmente, adicionado em $5 \%$ em volume ao diesel de petróleo, mas há estudos para aumentar este percentual para até $10 \%$ nos próximos anos. A principal limitação à produção do etanol de $1^{\text {a }}$ geração hoje em dia diz respeito a sua competição com alimentos. O preço internacional do açúcar comum (sacarose), de certa forma, regula a oferta de etanol para fins energéticos no país. Já o biodiesel enfrenta outros desafios, que vão desde a busca por matérias-primas mais eficientes, que proporcionem maior produtividade e menor custo de produção, até melhorias no processo produtivo do biocombustível. O uso de microalgas ${ }^{7}$ aparece como uma alternativa interessante, pois pode aumentar bastante a produtividade em óleo. Por outro lado, o desenvolvimento de catalisadores heterogêneos para o processo de transesterificação precisa ser acelerado. Atualmente, os catalisadores usados industrialmente são homogêneos, como o hidróxido e o metóxido de sódio, que apesar de terem alta atividade geram grandes quantidades de resíduos, oriundos da lavagem do biocombustível, além de serem perdidos no processo. Catalisadores a base de complexos metálicos, assim como sólidos básicos, aparecem como fortes candidatos ${ }^{8}$ para serem utilizados nos processos de produção de biodiesel. A busca por catalisadores heterogêneos para produção de biodiesel também pode permitir a melhor utilização da glicerina, co-produto de produção deste biocombustível. Isso porque, em geral, os catalisadores heterogêneos fornecem uma glicerina de melhor qualidade, sem tantas impurezas que podem afetar sua posterior conversão em produtos de maior valor agregado.

\section{Biocombustíveis de $2^{\mathrm{a}}$ geração}

Os biocombustíveis de $2^{\mathrm{a}}$ geração são aqueles que utilizam como matéria-prima a biomassa lignocelulósica, podendo esta se originar a partir dos resíduos agrícolas e do processamento da madeira. Destacam-se nesta categoria o etanol celulósico ${ }^{9}$ e a produção de hidrocarbonetos na faixa de combustíveis líquidos por processos de conversão termoquímica. ${ }^{10,11}$ Estes biocombustíveis poderiam ser produzidos nas chamadas biorrefinarias, em alusão à própria infraestrutura da indústria de petróleo, com suas refinarias centralizadas. Entretanto, a baixa densidade da biomassa elevaria os custos de transporte, tornando a logística ineficiente e afetando a viabilidade econômica de todo o processo. Desta forma, a produção de biocombustíveis de $2^{\text {a }}$ geração, além de requerer investimentos na área de P\&D para garantia de competitividade frente aos combustíveis fósseis, tem um modelo de produção que tende à descentralização, com pequenas refinarias bem próximas à biomassa a ser processada.

Um dos desafios técnicos a ser superado para a produção do etanol celulósico é a recalcitrância da biomassa lignocelulósica, ou seja, a sua elevada resistência à degradação. ${ }^{12}$ É preciso, inicialmente, separar e concentrar as partes constituintes individuais da biomassa, ou seja, a lignina ( $26 \%$ em peso) da celulose ( $45 \%$ em peso) e esta da hemicelulose (29\% em peso). A celulose e a hemicelulose são polímeros cristalinos que precisam ser degradados ou despolimerizados a seus açúcares primários, glicose e xilose, respectivamente. Estes, uma vez disponíveis em abundância, são convertidos no etanol, dito celulósico, por processos fermentativos tradicionais. Várias tecnologias de pré-tratamento da celulose empregam processos químicos, físicos ou biológicos. Os processos químicos são insustentáveis do ponto de vista ambiental devido à grande utilização de ácidos ou bases inorgânicas, assim como temperaturas e pressões elevadas. Os processos físicos como a moagem são ineficientes, mas transformam a (hemi)celulose de uma estrutura cristalina para uma fase amorfa, aumentando a sua degradabilidade e, portanto, o rendimento de glicose e xilose em etapa posterior de despolimerização. Os processos biológicos consistem na descoberta de microorganismos, fungos ou bactérias, capazes de digerir a (hemi)celulose em seus açúcares primários. A hidrólise enzimática é uma das formas de degradação de maior prática na indústria, mas de custo elevado. Recentemente, têm sido desenvolvidos processos que utilizam a catálise heterogênea para a despolimerização da (hemi)celulose. Catalisadores sólidos ácidos como materiais carbonáceos de alta área superficial e funcionalizados

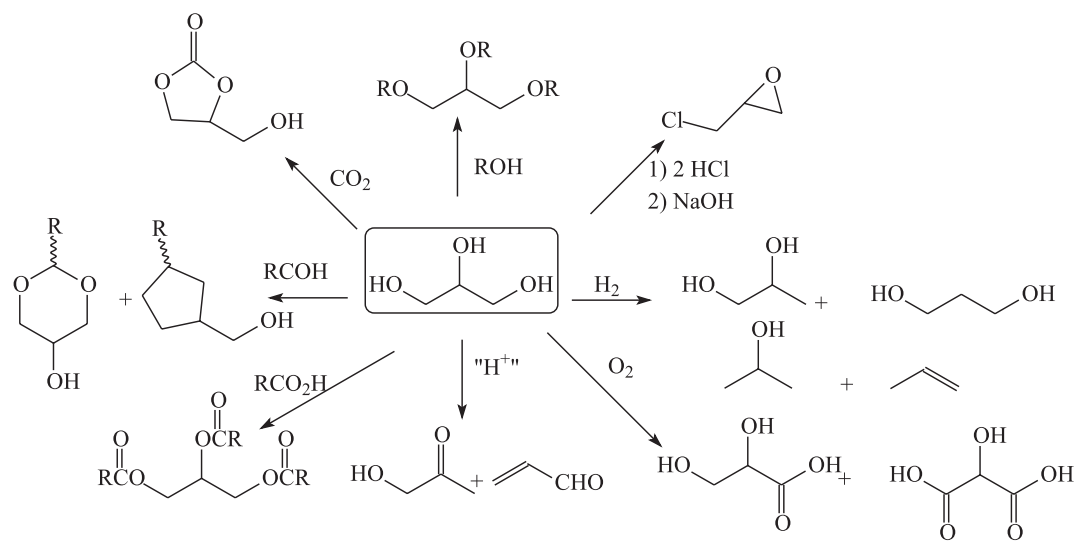

Figura 3. Algumas transformações químicas para a glicerina de produção de biodiesel 
Tabela 1. Rendimento de etanol celulósico a partir de 1 tonelada de palha de milho ${ }^{14}$

\begin{tabular}{lcllc}
\hline \multicolumn{2}{c}{ Etanol (a partir da Glicose) } & & & Etanol (a partir da Xilose) \\
\hline Palha de milho & $1.000 \mathrm{~kg}$ & Palha de milho & $1.000 \mathrm{~kg}$ & $29 \%$ \\
Teor de celulose & $45 \%$ & Teor de hemicelulose & & \\
Conversão da celulose e eficiência na recuperação & $76 \%$ & Conversão da hemicelulose e eficiência na recuperação & $90 \%$ \\
Rendimento estequiométrico em etanol & $51 \%$ & Rendimento estequiométrico em etanol & $51 \%$ \\
Eficiência da fermentação da glucose & $75 \%$ & Eficiência da fermentação da xilose & $50 \%$ \\
Rendimento final em etanol & $131 \mathrm{~kg}(145 \mathrm{~L})$ & Rendimento final em etanol & $66 \mathrm{~kg}(76 \mathrm{~L})$ \\
\hline
\end{tabular}

com grupos ácidos de Brönsted como $-\mathrm{SO}_{3} \mathrm{H},-\mathrm{COOH},-\mathrm{OH},{ }^{13}$ além de óxidos puros e mistos de metais de transição como zircônio, nióbio e tungstênio, apresentam elevados rendimentos, próximos a $80 \%$, em glicose livre. Nestes processos, a (hemi)celulose é previamente moída em moinhos de bolas de alta rotação para obtenção de fase amorfa, mais suscetível a degradação, e posteriormente misturada com o catalisador heterogêneo. O sistema é então submetido à alta pressão e temperatura. Os rendimentos típicos de etanol celulósico obtidos, por exemplo, a partir de uma tonelada de uma biomassa importante, como a palha de milho, atingem cerca de $76 \%$ para a glicose e cerca de $90 \%$ para a xilose. Entretanto, se levar em consideração a biomassa bruta, o rendimento não passa de $15 \%$ (Tabela 1). ${ }^{14}$ Em outras palavras, a eficiência total de conversão a partir da biomassa bruta ainda é muito baixa, com a consequente geração de grande quantidade de resíduos. Estes resíduos, por sua vez, poderiam ser utilizados em processos de conversão térmica para a produção de hidrocarbonetos líquidos ou simplesmente queimados para produção de energia.

A conversão termoquímica de biomassa lignocelulósica, por meio da gaseificação ou da pirólise, tem sido empregada para a produção de hidrocarbonetos na faixa de combustíveis líquidos como a gasolina, o querosene de aviação (QAV) e o óleo diesel. Na gaseificação da biomassa, o gás de síntese, uma mistura de monóxido de carbono e hidrogênio, é produzido em razões molares que permitam uma posterior conversão em hidrocarbonetos por meio da síntese de FischerTropsch. ${ }^{11}$ Esta seria a tecnologia GTL (Gas to Liquids), desenvolvida e estabelecida para a conversão do gás natural, aplicada a produção de biocombustíveis. O próprio conceito da tecnologia GTL foi estendido para acomodar o carvão mineral e a biomassa passando, então, a ser conhecido como processo XTL, onde $\mathrm{X}$ se refere à matéria prima empregada (G: gás; C: carvão; e B: biomassa) (Esquema 3).

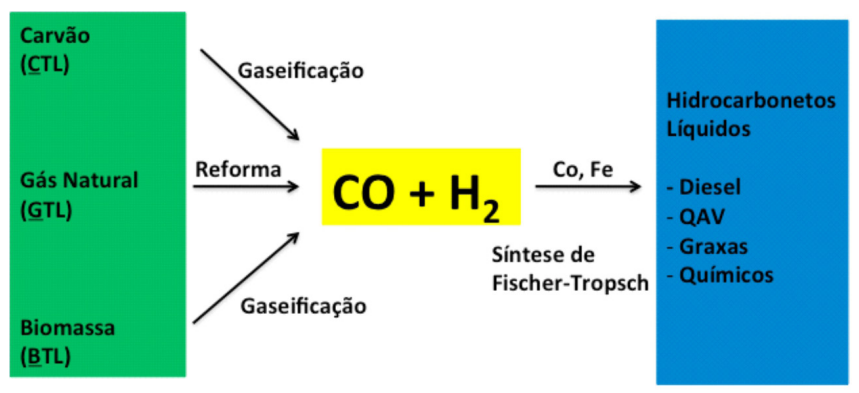

Matéria prima

Gás de síntese

Produtos finais

Esquema 3. Processo XTL

A extensa variabilidade de biomassa e de resíduos agrícolas é um dos principais problemas para os processos de gaseificação, uma vez que os gaseificadores são projetados para processar matéria-prima com uniformidade de composição. Gaseificadores mais versáteis, aliados a uma boa logística de coleta e uniformização de biomassa, são fundamentais para a produção de um gás de síntese adequado ao processo de Fischer-Tropsch. Embora seja possível obter até 85\% em rendimento de gases contendo, basicamente, $\mathrm{CO}, \mathrm{H}_{2}$ e um pouco de $\mathrm{CH}_{4}$, a razão $\mathrm{CO} / \mathrm{H}_{2}$ típica para a síntese de Fischer-Trospch é de 2 para a produção de hidrocarbonetos líquidos. Este parâmetro de processo precisa ser atingido independente da natureza da biomassa a ser gaseificada. Uma das maneiras investigadas para a diminuição da variabilidade é a produção do biocarvão como produto intermediário, ajudando, ainda, na diminuição do custo logístico de transporte por densificar a biomassa. Portanto, os gaseificadores operariam com biocarvão e não biomassa in natura. A viabilidade técnica do processo BTL (Biomass to Liquids) foi demonstrada na Alemanha, em 2009, a partir de uma bem sucedida construção de uma planta de gaseificação (Carbo- $\mathrm{V}^{\circledR}$ - CHOREN GmbH) acoplada a síntese de Fischer-Tropsch (processo Shell), em escala piloto, com capacidade de processamento de 65.000 ton/ano de biomassa, correspondendo a 18 milhões de litros de produtos líquidos. ${ }^{15}$ Apesar da versatilidade da etapa de gaseificação, capaz de processar diferentes tipos de biomassa seca, como madeira e resíduos agrícolas, o processo se mostrou inviável economicamente para uma planta em escala industrial, levando à insolvência da CHOREN GmbH após anos de investimento na tecnologia. O grupo alemão Linde $\mathrm{AG}$ acabou adquirindo a tecnologia de gaseificação Carbo-V ${ }^{\circledR}$ da Choren em $2012 .{ }^{16}$ Cabe ressaltar a total ausência de subsídios governamentais neste desenvolvimento, o que mostra que sem incentivos a biomassa ainda tem baixa competitividade frente à matéria-prima de origem fóssil.

Outra tecnologia para a conversão termoquímica da biomassa é a pirólise. Dos diferentes tipos possíveis de conduzir um processo de pirólise, seja na forma convencional, flash ou rápida, a pirólise rápida tem sido a mais adequada para a conversão de biomassa, por causa do maior rendimento (> 80\%) e da natureza mais próxima a combustíveis fósseis dos produtos líquidos formados, conhecido como bio-óleo. ${ }^{9}$ $\mathrm{Na}$ pirólise rápida prevalecem elevadas taxas de aquecimento (200 a $10^{5}{ }^{\circ} \mathrm{C}$ por segundo) e temperaturas na faixa de 800 a $1000{ }^{\circ} \mathrm{C}$ com tempo de residência baixíssimo, na casa dos milisegundos. O produto obtido é o chamado bio-óleo, um líquido escuro, ácido e altamente reativo, devido a presença de insaturações, que se não for estabilizado, a viscosidade cresce rapidamente até completa solidificação. A composição típica de um bio-óleo de pirólise rápida da madeira e as suas propriedades físico-químicas são mostrados na Tabela $2,{ }^{17}$ sendo ainda comparadas com as do petróleo. O bio-óleo tem bastante quantidade de água e compostos oxigenados, além de baixo poder calorífico, acidez e viscosidade elevadas. Com estas propriedades, o uso direto do bio-óleo como combustível é limitado, sendo necessário seu beneficiamento para torná-lo adequado ao uso como combustível de transporte para veículos automotores. Neste contexto, a tecnologia de hidrotratamento de frações de petróleo, amplamente difundida nas refinarias convencionais, está sendo utilizada para o beneficiamento de bio-óleo. Entretanto, por causas das características físico-químicas do bio-óleo, é necessário o desenvolvimento de novos catalisadores heterogêneos que possuam propriedades como tolerância à água e resistência a acidez, bem como funções catalíticas de desoxigenação, 
hidrogenação e craqueamento. Catalisadores bifuncionais contendo metais suportados em sólidos ácidos se destacam por aproximar as propriedades do bio-óleo hidrotratado às da gasolina convencional (Tabela 3). ${ }^{18}$

Tabela 2. Características físico-químicas do bio-óleo oriundo da pirólise rápida da madeira ${ }^{17}$

\begin{tabular}{lcc}
\hline Composição & $\begin{array}{c}\text { Petróleo } \\
\text { Bruto }\end{array}$ & $\begin{array}{c}\text { Bio-Óleo } \\
\text { de Madeira }\end{array}$ \\
\hline $\mathrm{C}, \%$ & $83-86$ & $32-44$ \\
$\mathrm{H}, \%$ & $11-14$ & $7,5-8,6$ \\
$\mathrm{~S}, \%$ & $0-4$ & 0,2 \\
$\mathrm{~N}, \%$ & $0-1$ & $0,1-0,7$ \\
O, \% & - & $44-55$ \\
Razão H/C & $1,8-1,9$ & 1,4 \\
Densidade (g.cm ${ }^{-3}$ ) & 0,86 & 1,17 \\
TAN (no. de acidez total) & $<1$ & $>100$ \\
Metais alcalinos, ppm & 60 & 100 \\
Poder calorífico, BTU & 41.800 & 15.200 \\
\hline
\end{tabular}

Tabela 3. Bio-óleo hidrotratado em comparação a composição típica da gasolina $^{18}$

\begin{tabular}{lccc}
\hline \multirow{2}{*}{ Composição } & \multicolumn{2}{c}{ Bio-óleo hidrotratado de madeira } & \multirow{2}{*}{ Gasolina típica } \\
\cline { 2 - 3 } & Mín. & Máx. & \\
\hline Parafinas, \% & 5,2 & 9,5 & 44,2 \\
Isoparafinas, \% & 16,7 & 24,9 & 35 \\
Olefinas, \% & 0,6 & 0,9 & 4,1 \\
Naftênicos, \% & 39,6 & 55,0 & 7 \\
Aromáticos, \% & 9,9 & 34,6 & 38 \\
Oxigenados, \% & - & 0,8 & - \\
\hline
\end{tabular}

\section{Biocombustíveis de $3^{\text {a }}$ geração}

Biocombustíveis de $3^{\text {a }}$ geração podem ser originados de biomassa cultivada para este propósito e que não tenha nenhuma competição com a produção de alimentos, como as algas. ${ }^{19} \mathrm{O}$ aproveitamento do lixo urbano orgânico como matéria-prima se enquadra, também, em algumas definições nesta categoria. Embora o cultivo de algas, por seu alto rendimento em lipídeos, tem sido apontado como a matéria-prima que garante a competitividade dos biocombustíveis em substituição aos fósseis, outras substâncias de grande valor industrial como alimentos, produtos farmacêuticos e cosméticos também podem ser produzidos. Dependendo da espécie de alga a ser cultivada, é possível obter antibióticos, ácidos graxos poliinsaturados, triglicerídeos, enzimas, proteínas, vitaminas e antioxidantes. ${ }^{19}$ Portanto, a versatilidade de produtos a serem comercializados, sejam biocombustíveis ou especialidades para as indústrias químicas e de alimentos, será a característica da indústria de algas para que a sustentabilidade e a competitividade econômica sejam atingidas.

As algas podem ser cultivadas com impacto mínimo ao meio ambiente em águas residuais e salinas. Os rendimentos são de 10 a 100 vezes mais de combustível por unidade de área do que os biocombustíveis de $1^{\text {a }}$ e $2^{\text {a }}$ geração. Entretanto, devido aos altos custos operacionais, o preço de produção chega a US \$ 5.000 por tonelada no caso de algas de grau alimentar. Outro desafio é o alto teor de água nas algas, que precisa ser removida por centrifugação ou filtração antes da extração dos lipídeos. Os triglicerídeos obtidos podem ser transesterificados em típica tecnologia de produção para o biodiesel de $1^{\text {a }}$ geração ou sofrer hidrogenólise rendendo alcanos na faixa do óleo diesel e QAV. Biocombustíveis de algas permanecem em intensa controvérsia sobre a sua real viabilidade econômica. Após investir mais de US \$ 600 milhões em tecnologia genética para a produção de algas desde 2009, a ExxonMobil anunciou em 2013 que será preciso mais 25 anos para atingir a viabilidade econômica. ${ }^{20}$ Por outro lado, uma pequena empresa de capital de risco, Algenol, reivindica a capacidade de produção de 33.750 litros de etanol, equivalente a um acre ou 0,4 ha de terra, a partir de algas. A empresa anuncia a produção comercial em $2014 .^{21}$

Dentre os desafios alinhados na área do uso de microalgas para fins energéticos podemos citar a melhoria dos processos produtivos, com redução de custos e integração com usinas termelétricas, para captação do $\mathrm{CO}_{2}$ gerado e a otimização do processo de extração do óleo. Outro ponto que merece destaque é a alta quantidade de insaturações normalmente presente nos óleos oriundos de algas. Isto pode comprometer sua utilização como biodiesel, já que o número de insaturações na cadeia está diretamente relacionado com a resistência à oxidação do biodiesel, requerendo a adição de grandes quantidades de antioxidantes na formulação final do biocombustível. Outra opção seria a hidrogenação total ou parcial das duplas ligações, mas neste caso o custo seria alto, pois os processos requerem hidrogênio e altas pressões.

\section{CONVERSÃO DO $\mathrm{CO}_{2}$}

O dióxido de carbono é um gás produzido em processos de combustão de matéria orgânica. Por muitos anos ele foi considerado um reagente inerte e de pouco interesse para fins industriais. Seu uso em processos químicos está associado, basicamente, a produção de uréia, através da reação com amônia.

Com a crescente emissão e acúmulo deste gás na atmosfera, ele se tornou um dos principais vilões do aquecimento global. $\mathrm{O}$ uso de biocombustíveis pode, em parte, minimizar os efeitos deste gás no clima do planeta, já que, pela fotossíntese, ele é absorvido por plantas e outros organismos vivos. Entretanto, o aumento da concentração de $\mathrm{CO}_{2}$ na atmosfera avança num ritmo muito maior do que poderia ser captado via fotossíntese, levando a um acúmulo crescente, que pode desencadear grandes mudanças climáticas. A captura do $\mathrm{CO}_{2}$ produzido em termelétricas, ou mesmo de complexos industriais, é um assunto de importância crescente. Cada vez mais será necessário diminuir as emissões deste gás para a atmosfera, e todo esforço neste sentido será bem vindo. Por outro lado, a captura e armazenamento geram custos adicionais e, atualmente, uma das principais soluções está no aproveitamento e utilização deste $\mathrm{CO}_{2}$, de forma a agregar valor econômico. Desta maneira, o uso de $\mathrm{CO}_{2}$ como matéria-prima industrial aparece como uma alternativa interessante.

$\mathrm{O}$ grande problema nas rotas de transformação química do $\mathrm{CO}_{2}$ está na limitação energética para vencer a grande estabilidade termodinâmica deste gás, e sua baixa reatividade química. A Figura 4 define três classes de transformações químicas quanto ao estado de oxidação do átomo de carbono. ${ }^{22}$ As rotas horizontais, que englobam os carbonatos orgânicos, uréia e carbamatos não envolvem modificação do estado de oxidação do átomo de carbono, sendo, em geral, menos demandantes em termos energéticos. As rotas verticais, que levam a monóxido de carbono, ácido fórmico, formaldeído, metanol e metano são, em geral, mais energéticas, pois envolvem a redução do átomo de carbono da molécula de $\mathrm{CO}_{2}$. Por fim, as rotas ditas diagonais, que incluem a produção de hidrocarbonetos e alcoóis de maior cadeia, estão num meio termo com relação ao gasto energético. Todavia, é importante perceber que a termodinâmica não favorece 
os processos de conversão de $\mathrm{CO}_{2}$, sendo necessário suprir energia ao sistema e lançar mão de técnicas de remoção de subprodutos e reciclo, de forma a se poder obter níveis aceitáveis de conversão e rentabilidade.

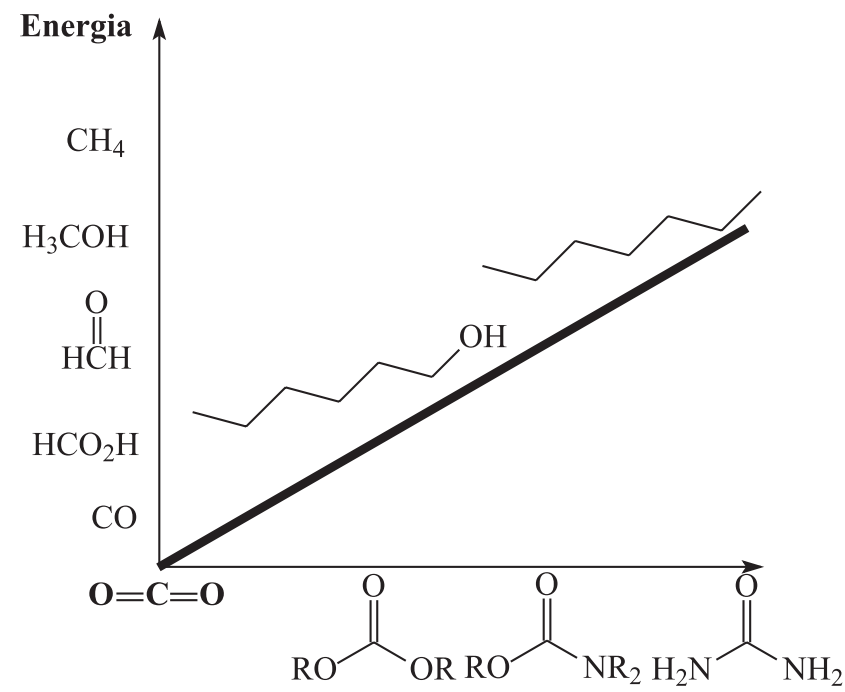

Figura 4. Processos de transformação química do $\mathrm{CO}_{2}$. Relação entre o gasto energético e o estado de oxidação do átomo de carbono no produto final (adaptado da referência 22)

\section{Hidrogenação a metanol}

Uma das rotas de maior interesse industrial para a fixação química do $\mathrm{CO}_{2}$ é a sua hidrogenação a metanol $\left(\mathrm{CO}_{2}+3 \mathrm{H}_{2} \leftrightarrows \mathrm{CH}_{3} \mathrm{OH}+\mathrm{H}_{2} \mathrm{O}\right.$, $\left.\Delta H_{50 \mathrm{bar}, 298 \mathrm{~K}}=-21,62 \mathrm{kcal} / \mathrm{mol}\right)$. Além do seu uso direto como combustível ou solvente, o metanol é matéria prima na produção de olefinas por meio do processo MTO (Methanol to Olefins). Atualmente, grande parte do metanol produzido no mundo é originado do gás de síntese, utilizando catalisadores à base de cobre e zinco, pressão de 100 bar e temperatura na faixa de 220 a $300{ }^{\circ} \mathrm{C}$. A hidrogenação do $\mathrm{CO}_{2}$ a metanol também pode fazer uso dos mesmos catalisadores à base de $\mathrm{Cu}$ e Zn. Entretanto, a reação é restringida fortemente pelo equilíbrio termodinâmico. A produção do metanol é favorecida à alta pressão e baixa temperatura. A ocorrência da reação reversa do gás d'água $\left(\mathrm{CO}_{2}\right.$ $+\mathrm{H}_{2} \leftrightarrows \mathrm{CO}+\mathrm{H}_{2} \mathrm{O}, \Delta H_{50 \text { bar, } 298 \mathrm{~K}}=+9,82 \mathrm{kcal} / \mathrm{mol}$ ) é beneficiada a altas temperaturas com a maior formação de monóxido de carbono $(\mathrm{CO})$. A Figura 5 mostra o efeito da temperatura da reação na taxa de produção do metanol a pressão de 50 bar para um catalisador de $\mathrm{Cu} / \mathrm{Zn} /$ $\mathrm{Al}(50 / 40 / 10 \mathrm{~mol} \%)$ de referência. Nota-se que para esta formulação catalítica a taxa de produção do metanol se aproxima do equilíbrio a $270{ }^{\circ} \mathrm{C}$. Em temperaturas mais baixas, a atividade do catalisador é pequena, bem abaixo do equilíbrio. Este resultado mostra que a hidrogenação de $\mathrm{CO}_{2}$ tem limitações cinéticas para catalisadores a base de $\mathrm{Cu}$ e $\mathrm{Zn}$ e que, portanto, catalisadores mais ativos, capazes de operar a baixas temperaturas, precisam ser desenvolvidos, tornando os processos de conversão de $\mathrm{CO}_{2}$ a metanol, em escala industrial, mais eficientes e econômicos. ${ }^{23}$ Uma saída para esta questão é investigar o uso de promotores catalíticos, que aumentem a atividade sem afetar a seletividade a metanol. Os promotores têm papel de aumentar a área específica do cobre, propiciando melhor dispersão metálica.

Outro desafio importante na busca de um processo eficiente de conversão de $\mathrm{CO}_{2}$ a metanol é a fonte de hidrogênio. Atualmente, o hidrogênio é produzido, principalmente, a partir da reforma do gás natural, usando catalisadores a base de níquel. A biomassa, por meio de processos BTL discutidos anteriormente, também poderia ser fonte de hidrogênio, mas em qualquer processo que envolva

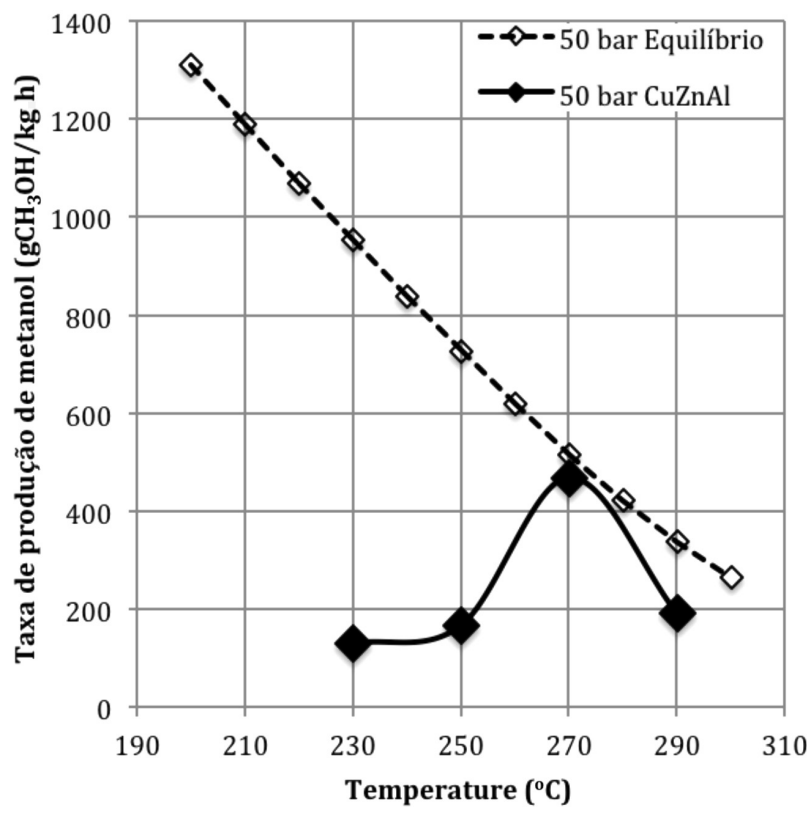

Figura 5. Taxa de produção de metanol a partir da hidrogenação do $\mathrm{CO}_{2}$ em função da temperatura de reação a 50 bar $^{23}$

matéria-prima de origem orgânica, monóxido de carbono será produzido concomitantemente. Outras fontes de hidrogênio são o processo de craqueamento a vapor de nafta, usado em centrais petroquímicas para produção de olefinas leves, e plantas eletroquímicas de produção de $\mathrm{NaOH} \mathrm{e} \mathrm{Cl}_{2}$, onde hidrogênio é um subproduto.

A produção sustentável de hidrogênio, sobretudo a partir da decomposição da água, é um dos principais desafios em processos de hidrogenação de $\mathrm{CO}_{2}$. Estudos sobre a decomposição fotocatalítica da água, usando novos materiais e sensibilizadores para permitir a absorção de luz visível, assim como processos eletrolíticos mais eficientes precisam ser mais aprofundados. Vale salientar que, recentemente, uma planta industrial de produção de metanol a partir de $\mathrm{CO}_{2}$ foi aberta na Islândia, ${ }^{24}$ fazendo uso de hidrogênio gerado a partir da eletrólise da água com energia geotérmica. O Brasil possui grande potencial hidrelétrico, que pode ser aproveitado em processos de eletrólise mais eficientes. O nosso território é, também, um dos mais privilegiados no planeta em relação à energia solar, que pode ser captada em processos para decomposição fotocatalítica da água.

\section{Produção de hidrocarbonetos}

Hidrocarbonetos na faixa da gasolina e do óleo diesel podem ser obtidos a partir do $\mathrm{CO}_{2}$ por meio de duas rotas: a reação reversa de gás d'água (RWGS) acoplada à síntese de Fischer-Tropsch (FT) (Esquema 4), ou pela hidrogenação a metanol seguida de transformação química deste produto a hidrocarbonetos (MTH) ${ }^{25} \mathrm{~A}$ primeira rota tem sido mais estudada na literatura, sobretudo para a produção de olefinas leves usadas na produção de plásticos. A reação reversa de gás d'água é endotérmica, e, normalmente, realizada na presença de catalisadores à base de cobre e cromo. Já a síntese de FischerTropsch é exotérmica e ocorre na presença de catalisadores de ferro ou cobalto. O grande desafio é formular um sistema catalítico capaz de realizar as duas reações simultaneamente, em um único passo.

$$
\begin{aligned}
& \mathrm{CO}_{2}+\mathrm{H}_{2} \rightleftharpoons \mathrm{CO}+\mathrm{H}_{2} \mathrm{O} \quad \Delta \mathrm{H}=+10 \mathrm{kcal} / \mathrm{mol} \quad(\mathrm{RWGS}) \\
& \left.\mathrm{n} \mathrm{CO}+2 \mathrm{n} \mathrm{H}_{2} \longrightarrow-\mathrm{CH}_{2}-\right]_{\mathrm{n}}+\mathrm{n} \mathrm{H}_{2} \mathrm{O} \quad \Delta \mathrm{H}=-49 \mathrm{kcal} / \mathrm{mol}(\mathrm{FT})
\end{aligned}
$$

Esquema 4. Reação reversa de gás d'água (RWGS) e síntese de Fischer-Tropsch (FT) para conversão do $\mathrm{CO}_{2}$ em hidrocarbonetos 
Nosso grupo tem estudado o emprego de zeólitas impregnadas com diferentes metais para acoplar as duas reações. O objetivo é produzir olefinas leves, preferencialmente, eteno e propeno. A Figura 6 mostra a conversão de $\mathrm{CO}_{2}$ a hidrocarbonetos sobre uma zeólita impregnada com ferro e outros promotores metálicos. A pressão exerce um efeito importante sobre a distribuição de produtos na temperatura de $450{ }^{\circ} \mathrm{C}$. Hidrocarbonetos de maior cadeia (C4+) são favorecidos a pressões mais elevadas, em detrimento do metano, que é preferencialmente formado à pressão atmosférica.

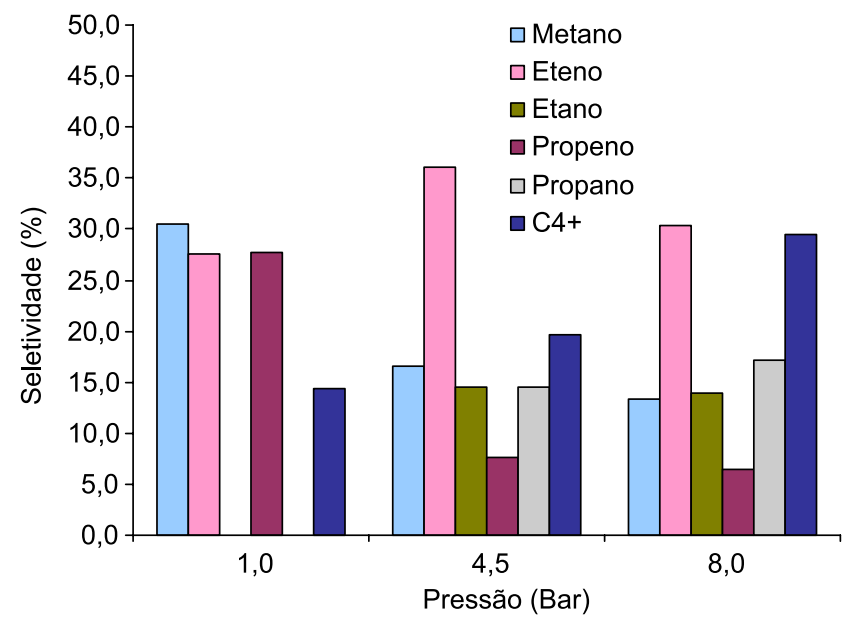

Figura 6. Efeito da pressão sobre a distribuição de hidrocarbonetos na conversão de $\mathrm{CO}_{2}$ sobre zeólita impregnada com ferro (razão molar $\mathrm{H}_{2}: \mathrm{CO}_{2}$ $\left.3: 1, T=450{ }^{\circ} \mathrm{C}\right)$

A questão do hidrogênio é também importante em processos de hidrogenação de $\mathrm{CO}_{2}$ a hidrocarbonetos, requerendo rotas baseadas na decomposição da água ao invés do uso de matéria fóssil.

\section{Produção de carbonatos orgânicos}

$\mathrm{O}$ uso de $\mathrm{CO}_{2}$ para produção de plásticos é uma alternativa bastante interessante para fixação deste gás do efeito estufa. Enquanto a produção de olefinas leves, discutida anteriormente, se encaixa na rota diagonal descrita na Figura 4, a produção de carbonatos orgânicos a partir do $\mathrm{CO}_{2}$ é uma rota horizontal, na qual o estado de oxidação do átomo de carbono não é modificado, envolvendo um menor gasto energético no processo de produção.

O carbonato de metila (DMC), ${ }^{26}$ o carbonato de etileno (CE) e o carbonato de glicerina (CG) aparecem, atualmente, como os principais carbonatos orgânicos de interesse industrial. Todos podem ser utilizados na fabricação de policarbonatos, que são polímeros com uso crescente, dada sua alta resistência ao impacto e transparência. O DMC também pode ser usado como aditivo para combustíveis e o CG tem uso como solvente.

O CE é obtido industrialmente pela reação do $\mathrm{CO}_{2}$ com óxido de etileno. Numa segunda etapa, o CE pode reagir com metanol em excesso para formar o DMC (Esquema 5). A empresa Asahi Kasei Chemical produz cerca de 50 mil toneladas ano de policarbonatos utilizando esta rota, possibilitando uma diminuição na emissão de $\mathrm{CO}_{2}$ na atmosfera de 1.730 toneladas para cada 10.000 toneladas de policarbonato produzidas.

A produção direta de DMC via reação do $\mathrm{CO}_{2}$ com metanol também tem sido bastante estudada na literatura. ${ }^{26}$ Entretanto, os rendimentos são baixos, pois a água formada como subproduto desloca o equilíbrio e também pode afetar os catalisadores utilizados.

O carbonato de glicerina é normalmente obtido pela reação do glicerol com uréia, na presença de sais de zinco. ${ }^{27}$ Como a uréia é

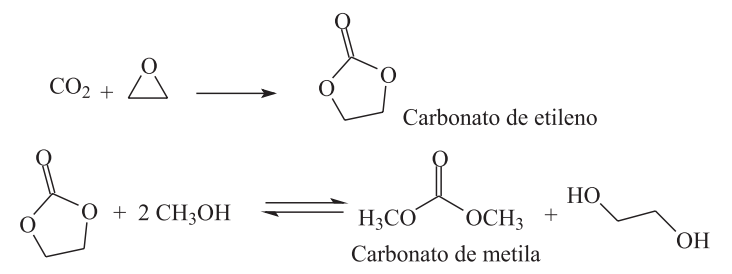

Esquema 5. Produção do carbonato de etileno e carbonato de metila. Rota da Asahi Kasei Chemical

obtida industrialmente a partir do $\mathrm{CO}_{2}$, esta rota pode ser considerada como oriunda deste gás. A carbonatação direta do glicerol é menos estudada (Esquema 6). O uso de catalisadores homogêneos, à base de complexos de estanho, produzem um rendimento de 5,5 $\%$ no carbonato de glicerina. ${ }^{28}$ Nosso grupo vem estudando o uso de catalisadores heterogêneos e condições supercríticas nesta reação, obtendo até $7 \%$ de rendimento no carbonato de glicerina com o uso de catalisadores e condições otimizadas. Este valor é bem próximo do equilíbrio termodinâmico previsto em estudos teóricos, ${ }^{29}$ mostrando que eventuais melhorias precisam passar pela remoção da água formada como subproduto.

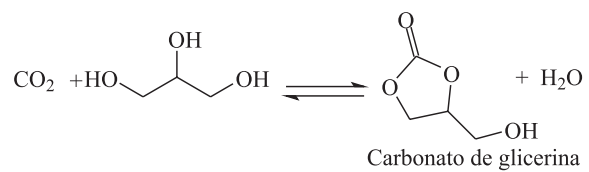

Esquema 6. Carbonatação do glicerol para produção do carbonato de glicerina

O grande desafio na produção de carbonatos orgânicos pela reação direta de alcoóis com $\mathrm{CO}_{2}$ é deslocar o equilíbrio termodinâmico da reação. Isto pode ser realizado pela remoção da água do meio, quer seja por meio físico, com uso de adsorventes, quer seja pela introdução de reagentes de sacrifício, que reagiriam preferencialmente com a água formada. Assim, além da pesquisa em novos e melhores catalisadores, sobretudo heterogêneos, desenvolvimentos processuais, no sentido de deslocar o equilíbrio, são fundamentais para que se tenham altas conversões e rendimentos de produto.

\section{CONSIDERAÇÕES FINAIS}

A Química deve buscar uma maior aproximação com a sociedade, mostrando que tem um papel essencial na vida de cada cidadão do planeta. O contexto da sustentabilidade precisa estar incluído em cada setor da Química, sobretudo na indústria, como se fosse parte inerente aos seus estudos.

Os biocombustíveis podem auxiliar neste ponto, permitindo uma transição mais harmoniosa na busca de uma matriz energética mais sustentável. É certo que não poderemos prescindir dos combustíveis fósseis a curto e médio prazo, mas eles terão um ciclo de vida limitado, quer seja pela depleção de suas reservas ou pelos graves efeitos que podem causar ao clima do planeta. Etanol e biodiesel podem auxiliar nesta jornada, neutralizando, ao menos parcialmente, as emissões de carbono na atmosfera. Há, porém, que se buscar matérias-primas e processos mais eficientes para produção de biocombustíveis, que não ofereçam competição com alimentos e tenham alta produtividade. Esta é uma interface interessante entre a Química e a Agronomia, que certamente terá lugar de destaque no século XXI.

Entretanto, os biocombustíveis não são a solução final. A substituição completa de combustíveis fósseis não é viável nem a longo prazo, visto que demandaria a utilização de vastas regiões agrícolas, com forte impacto ao meio ambiente. Além disto, a descoberta de 
grandes reservas de óleo no pré-sal, no litoral brasileiro, assim como o incremento do uso do gás de xisto, sobretudo nos Estados Unidos, sinaliza que os combustíveis fósseis continuarão sendo usados em larga proporção. Isto traz pressão ao meio ambiente, com a contínua emissão e acumulação de $\mathrm{CO}_{2}$ na atmosfera, afetando o clima do planeta. A resposta para este problema passa pela captura, armazenagem e utilização deste $\mathrm{CO}_{2}$, transformando-o em produtos químicos, e mesmo combustíveis.

A sustentabilidade é o principal desafio do século XXI. O século XIX viu o nascimento da revolução industrial e dos processos produtivos em larga escala, que se desenvolveram com o avanço nas ciências. O século XX consolidou as práticas industriais, com a ampliação do uso de combustíveis fósseis, vendo nascer a petroquímica, que incorporou os plásticos ao dia a dia das pessoas. Por outro lado, o uso crescente de combustíveis fósseis trouxe preocupações com a parte ambiental, a qual ficou sempre negligenciada nos dois séculos anteriores. O século XXI será o período da mudança de um modelo extrativista, que pouco se preocupa com o meio ambiente e os efeitos de longo prazo, para um modelo sustentável, que não abre mão das comodidades e benefícios que as práticas industriais trouxeram para a vida de cada um de nós, mas se preocupa em preservar o meio ambiente e os recursos naturais, para que as gerações futuras possam desfrutar dos mesmos benefícios. A Química não pode ficar fora deste contexto e precisa ocupar seu lugar, respondendo aos anseios e desafios da sociedade moderna.

\section{AGRADECIMENTOS}

C. J. A. Mota agradece ao CNPq e a FAPERJ por bolsas de pesquisa.

\section{REFERÊNCIAS}

1. Pinto, A. C.; Zuco, C.; Galembeck, F.; de Andrade, J. B.; Vieira, P. C.; Quim. Nova 2012, 35, 2092.

2. Poliakoff, M.; Fitzpatrick, J. M.; Farren, T. R.; Anastas, P. T.; Science 2002, 297, 807.

3. Anuário Estatístico da ANP 2012.

4. http://www.ethanolrfa.org/pages/statistics, acessada em Setembro 2013.

5. Pinto, A. C.; Guarieiro, L. N.; Resende, M. J. C.; Ribeiro, N. M.; Torres, E. A.; Lopes, W. A.; Pereira, P. A. D.; Andrade, J. B.; J. Braz. Chem. Soc. 2005, 16, 1313.

6. Mota, C. J. A.; da Silva, C. X. A.; Gonçalves, V. L. C.; Quim. Nova 2009, 32, 639 .
7. Pereira, C. M. P.; Hobuss, C. B.; Maciel, J. V.; Lizângela, R. F.; Del Pino, F. B.; Mesko, M. F.; Quim. Nova 2012, 35, 2013.

8. Suarez, P. A. Z.; Meneghetti, S. M. P.; Meneghetti, M. R.; Wolf, C. R.; Quim. Nova 2007, 30, 667.

9. Brethauer, S.; Wyman, C. E.; Bioresour. Technol. 2010, 101, 4862.

10. Balat, M.; Balat, M.; Kirtay, E.; Balat, H.; Energy Convers. Manage. 2009, 50, 3147.

11. Balat, M.; Balat, M.; Kirtay, E.; Balat, H.; Energy Convers. Manage. 2009, 50, 3158 .

12. Zheng, Y.; Pan, Z.; Zhang, R.; Int. J. Agr. Biol. Eng. 2009, 2, 51.

13. Yamaguchi, D.; Kitano, M.; Suganuma, S.; Nakajima, K.; Kato, H.; Hara, M.; J. Phys. Chem. C 2009, 113, 3181.

14. Badger, P. C.; Trends in New Crops and New Uses; Janic, J.; Whipkey, A., eds.; ASHS Press: Alexandria, 2002, p. 17.

15. http://www.biofuelstp.eu/spm2/pdfs/Matthias_Rudloff.pdf, acessada em Setembro 2013.

16. http://www.dieselnet.com/news/2012/021inde.php, acessada em Setembro 2013.

17. Mortensen, P. M.; Grunwaldt, J.-D.; Jensen, P. A.; Knudsen, K. G.; Jensen, A. D.; Appl. Catal., A 2007, 407, 1.

18. Holmgren, J.; Gosling, C.; Marinageli, R.; Faraci, G.; Perejo, C.; Hydrocarbon Processing 2007, 86, 67.

19. Brennan, L.; Owende, P.; Renewable Sustainable Energy Rev. 2010, 14 557.

20. http://www.bloomberg.com/news/2013-05-21/exxon-refocusing-algaebiofuels-program-after-100-million-spend.html, acessada em Setembro 2013

21. http://www.algenolbiofuels.com, acessada em Setembro 2013.

22. Gomes, C. N.; Jacquet, O.; Villiers, C.; Thury, P.; Ephritikhine, M.; Cantat, T.; Angew. Chem., Int. Ed. 2012, 51, 187.

23. Mota, C. J. A.; Monteiro, R. S.; Maia, E. B. V.; Pimentel, A. F.; Miranda, J. L., Alves, R. M. B.; Coutinho, P. L. A.; Revista Virtual de Química 2013, no prelo.

24. http://www.carbonrecycling.is, acessada em Setembro 2013.

25. Ilias, S.; Bhan, A.; ACS Catal. 2013, 3, 18.

26. Ferreira, H. B. P.; Vale, D. L.; Andrade, L. S.; Mota, C. J. A.; Miranda, J. L.; Revista Virtual de Química 2013, 5, 188.

27. Yoo, J. W.; Mouloungui, Z.; Stud. Surf. Sci. Catal. 2003, 146, 757.

28. Aresta, M.; Dibenedetto, A.; Nocito, F.; Pastore, C.; J. Mol. Catal. A: Chem. 2006, 257, 149.

29. Li, J.; Wang, T.; J. Chem. Thermodyn. 2011, 43, 731. 